\title{
Hot and Cold Nociception Are Genetically Correlated
}

\author{
Jeffrey S. Mogil and Seetal M. Adhikari \\ Department of Psychology and Neuroscience Program, University of Illinois at Urbana-Champaign, Champaign, Illinois \\ 61820
}

Recent experiments in our laboratory have revealed a genetic correlation of the sensitivity of inbred mouse strains to different assays of nociception using noxious heat stimuli. An open question is whether the property of the noxious stimulus underlying the genetic correlation is heat specifically or simply a temperature (hot or cold) in the noxious range. The existing electrophysiological, psychophysical, neurochemical, and functional imaging literatures regarding the relationship of heat pain and cold pain are quite contentious, with a number of similarities and dissociations being documented. In the present study, we tested 12 inbred mouse strains (129/J, A/J, AKR/J, BALB/cJ, C3H/HeJ, C57BL/6J, C57BL/10J, C58/J, CBA/J, $\mathrm{DBA} / 2 \mathrm{~J}, \mathrm{RIIIS} / \mathrm{J}$, and $\mathrm{SM} / \mathrm{J})$ for their reflexive withdrawal sensi- tivity to immersion of the tail in hot $\left(47.5^{\circ} \mathrm{C}\right)$ and cold $\left(-15^{\circ} \mathrm{C}\right)$ water and compared the observed latencies with those obtained previously, using a $49^{\circ} \mathrm{C}$ stimulus. All three traits displayed substantial heritabilities, ranging from 0.41 to 0.50 . Strain means on these nociceptive traits displayed a high degree of cross-correlation ( $r=0.49-0.77)$. Genetic correlation of hot and cold nociception implies that similar genes underlie interindividual variability in both traits in mice and further suggests that these nociceptive types share physiological mediation. This finding is discussed in relation to existing data in other mammals including humans.

Key words: thermal; pain; inbred strains; correlated responses; genetics; mice
Genetic variation in pain responses is starting to be elucidated (for review, see Mogil, 1999). Inbred mouse strains have been particularly useful toward this end, being advantageous (1) for establishing heritability estimates, (2) as progenitors of gene mapping efforts, and (3) for investigating genetic correlations among traits. We recently documented the sensitivity of 11 inbred mouse strains to 12 common measures of nociception (Mogil et al., 1999a). The measures tested spanned a wide range of noxious stimulus etiologies (nociceptive, inflammatory, and neuropathic), modalities (thermal, chemical, and mechanical), locations (cutaneous, subcutaneous, and visceral), and durations (acute, tonic, and chronic). By considering the genetic correlations among these strain sensitivities, we obtained evidence for the existence of three fundamental "types" of basal nociception: thermal, chemical, and mechanical (Mogil et al., 1999b). Assays within a type (i.e., a multivariate cluster) displayed far higher cross-correlations than assays between types.

The thermal cluster in that study consisted of the $49^{\circ} \mathrm{C}$ tailwithdrawal test (TW), the $53^{\circ} \mathrm{C}$ hot plate test (HP), Hargreaves' test of hindpaw withdrawal to radiant heat (HT), and, surprisingly, autotomy behavior after hindlimb denervation. The three former assays variously involve the tail or the hindpaw, reflexive or organized nocifensive responses, and different methods of introducing the noxious stimulus to the target tissue. However, they commonly use a thermal stimulus $>45^{\circ} \mathrm{C}$, in the noxious heat range of the mouse. The fact that autotomy shows genetic corre-

Received June 10, 1999; revised July 20, 1999; accepted July 20, 1999.

This work was supported by National Institutes of Health Grants DA11394 and DE12735 to J.S.M. Thanks to Brenda Edwards and her staff for excellent care of animals and to Sonya Wilson for assistance training S.M.A. Thanks also to Drs. William J. Roberts and Marshall Devor and the anonymous reviewers for helpful comments on this manuscript.

Correspondence should be addressed to Dr. Jeffrey S. Mogil, Department of Psychology, University of Illinois at Urbana-Champaign, 603 East Daniel Street,Champaign, IL 61820.

Copyright (C) 1999 Society for Neuroscience $\quad 0270-6474 / 99 / 190001-\bullet \$ 05.00 / 0$ lation with the TW, HP, and HT tests implies that the phantom pain possibly giving rise to this behavior may have a burning quality (Mogil et al., 1999b).

One of the unresolved questions from this work is whether the thermal measures are correlated because they all involve heat stimuli or simply extreme thermal stimuli. Exposure to very cold stimuli $\left(<0^{\circ} \mathrm{C}\right)$ can produce a sensation described by subjects as "burning," implying a similarity to noxious heat. Modern electrophysiological evidence implicates multimodal neurons in the dorsal horn of the spinal cord in the mediation of noxious cold as well as noxious heat; cold-specific neurons are thought to be primarily thermoreceptive in function (see Chen et al., 1996). However, various lines of evidence purport to dissociate hot and cold nociception. For example, exposure to noxious heat and cold has been demonstrated to variously cause release of somatostatin and substance P, respectively, in the spinal cord (Tiseo et al., 1990).

The purpose of the present study was, therefore, to specifically compare the sensitivities of 12 inbred mouse strains to noxious heat and noxious cold.

\section{MATERIALS AND METHODS}

Subjects. We chose to use naïve adult males of the 11 inbred mouse strains previously tested by Mogil et al. (1999a,b) (129, A, AKR,

This article is published in The Journal of Neuroscience, Rapid Communications Section, which publishes brief, peerreviewed papers online, not in print. Rapid Communications are posted online approximately one month earlier than they would appear if printed. They are listed in the Table of Contents of the next open issue of JNeurosci. Cite this article as: JNeurosci, 1999, 19:RC25 (1-5). The publication date is the date of posting online at www.jneurosci.org.

http://www.jneurosci.org/cgi/content/full/3466 


\section{A. $-15^{\circ} \mathrm{C}$ CTW Test}

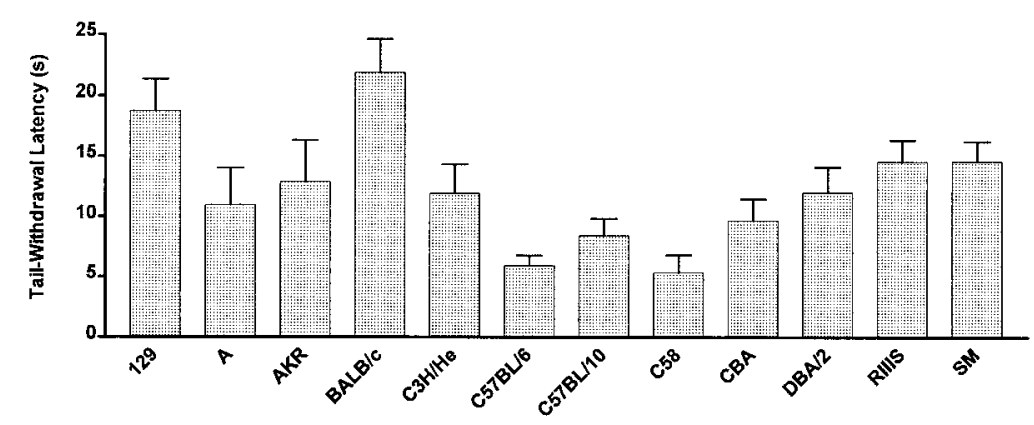

\section{B. $47.5^{\circ} \mathrm{C}$ TW Test}

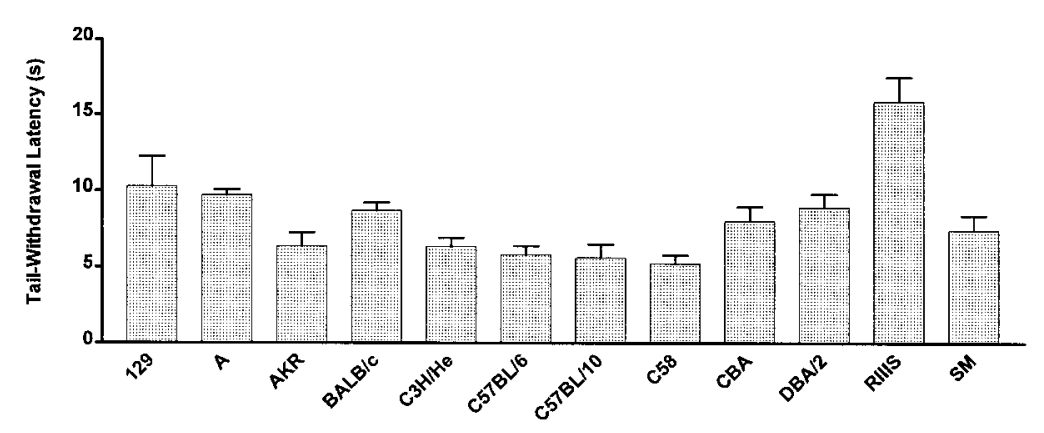

\section{C. $49^{\circ} \mathrm{C}$ TW Test}

Figure 1. Nociceptive sensitivity of 12 inbred mouse strains (all "J" substrains) to noxious cold and heat. Bars represent mean \pm SEM latencies to withdraw the distal half of the tail from $-15^{\circ} \mathrm{C}(A), 47.5^{\circ} \mathrm{C}(B)$, or $49^{\circ} \mathrm{C}(C)$ water in the $\mathrm{CTW}$ or TW assay. Individual latencies were determined twice, at $5 \mathrm{~min}(A, B)$ or $20 \mathrm{sec}(C)$ intervals, and averaged. Note the differing $y$-axis scales. Data in $C$ were collected in a previous study (Mogil et al., 1999a) and are shown for purposes of comparison.

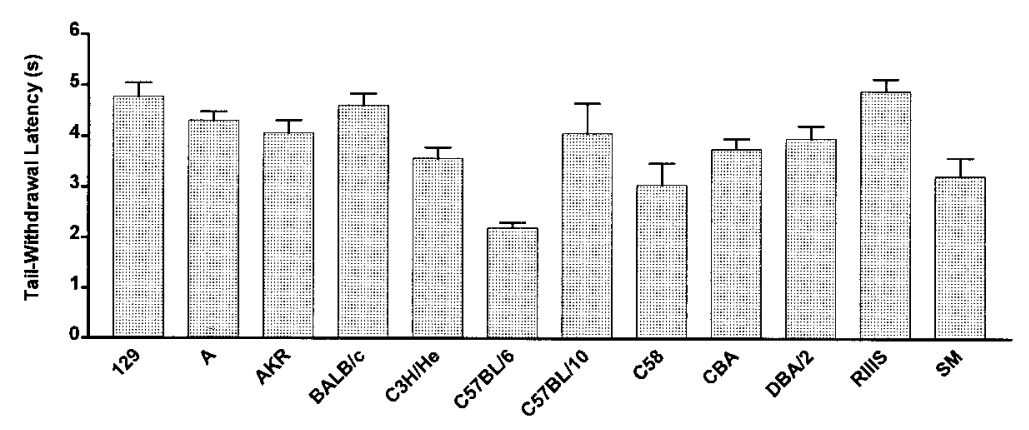

BALB/c, C3H/He, C57BL/6, C58, CBA, DBA/2, RIIIS, and SM; all "J" substrains purchased from The Jackson Laboratory, Bar Harbor, ME) plus the C57BL/10J mouse currently being tested in our laboratory. All mice were housed four per standard shoebox cage under a $12 \mathrm{hr}$ light/ dark cycle (lights on at 7 A.M.), with food and water available ad libitum.

Cold water nociception. Of the available rodent assays of noxious cold (e.g., cold plate and acetone spray), we chose to use the cold water tail-immersion/withdrawal test (CTW) of Pizziketti and colleagues (1985), because its application is identical in virtually all respects except temperature to the TW test. Ethanol was maintained within $1^{\circ} \mathrm{C}$ of the target temperature with a thermostatically controlled immersion cooling device (model IBC-4; Neslab Instruments, Portsmouth, NH). Extensive pilot experiments revealed that the optimal water temperature in the mouse was $-15^{\circ} \mathrm{C}$; intraindividual responses were unacceptably variable at higher temperatures, and at lower temperatures skin freezing occurred (see Daum et al., 1991), leading to immediate tail withdrawal in all strains. Although in the pilot outbred strain (Swiss Webster) repeated testing at $5 \mathrm{~min}$ intervals produced stable latencies, systematic latency increases (C57BL/10, DBA/2, and SM) and decreases (129) were noted with repeated testing in some inbred strains. Thus, we decided to test each mouse ( $n=5-9$ per strain) only twice for CTW sensitivity, at $5 \mathrm{~min}$ intervals. At each time point, mice were lightly restrained in a clothcardboard holder voluntarily entered by all subjects, and the distal half of their tail was immersed in ethanol. The time to vigorous withdrawal of the tail was measured to the nearest $0.1 \mathrm{sec}$ with a stopwatch. Mice were returned to their home cage in between latency determinations.

Hot water nociception. A separate group of mice from the same inbred strains were tested for hot water TW latencies. We chose to use a water temperature of $47.5^{\circ} \mathrm{C}$, because pilot experiments determined that this temperature was of equivalent stimulus intensity to $-15^{\circ} \mathrm{C}$, as evidenced by withdrawal latencies of outbred mice (data not shown). Unlike in the CTW experiment, in which for reasons of practicality mice bred in our laboratory were tested in order of availability (but always in counterbalanced sets of three strains and always within $2 \mathrm{hr}$ of midphotoperiod), the $47.5^{\circ} \mathrm{C} \mathrm{TW}$ experiment was completely counterbalanced. A recent forced depopulation of our colony necessitated the replacement of breeding stock of all 12 inbred strains from The Jackson Laboratory. The male breeders ( $n=5-9$ per strain), all 93-94 d old and all having arrived on the same day ( $>1$ week before testing), were tested en masse within a 90 min period (2:15-3:45 P.M.). Mice were tested exactly as in the CTW 


\begin{tabular}{|c|c|c|c|}
\hline Water temperature & $-15^{\circ} \mathrm{C}$ & $47.5^{\circ} \mathrm{C}$ & $49^{\circ} \mathrm{C}$ \\
\hline$-15^{\circ} \mathrm{C}$ & & 0.49 & $0.71^{*}$ \\
\hline $47.5^{\circ} \mathrm{C}$ & $0.67^{*}$ & & $0.70^{*}$ \\
\hline $49^{\circ} \mathrm{C}$ & 0.64 & $0.77^{*}$ & \\
\hline
\end{tabular}

${ }^{*} p<0.05$ after Bonferroni correction for multiple comparisons. The $r_{\mathrm{s}}$ between -15 and $49^{\circ} \mathrm{C}$ approached significance $(p=0.07)$.

experiment, in the same room and using the same restrainer, except that their tails were now immersed in water maintained at $47.5 \pm 0.5^{\circ} \mathrm{C}$ by a thermostatically controlled heater-circulator pump (Isotemp model 2100; Fisher Scientific, Pittsburgh, PA).

\section{RESULTS}

Three completed strain distributions are presented in Figure 1. Figure $1, A$ and $B$, illustrates strain means collected presently, in the $-15^{\circ} \mathrm{C} \mathrm{CTW}$ and $47.5^{\circ} \mathrm{C} \mathrm{TW}$ tests, respectively. Figure $1 C$ shows the data from the $49^{\circ} \mathrm{C} \mathrm{TW}$ test collected in our previous study (Mogil et al., 1999a); C57BL/10 mice were tested separately but using equivalent protocols.

One-way ANOVAs revealed significant main effects of strain in both the $-15^{\circ} \mathrm{C} \mathrm{CTW} \mathrm{test}\left(F_{(11,71)}=4.88 ; p<0.001\right)$ and the $47.5^{\circ} \mathrm{C}$ TW test $\left(F_{(11,64)}=5.89 ; p<0.001\right)$. Because individual members of inbred strains are isogenic, genetically identical at virtually all loci, between-strain variance provides an estimate of additive genetic variation, whereas within-strain variance represents environmental variability (Falconer and Mackay, 1996). Thus, we estimated narrow-sense heritability $\left(h^{2}\right)$ of these traits as 0.43 and 0.50 , respectively. These estimates, likely to be fairly accurate because strains were chosen randomly (Hegmann and Possidente, 1981), are similar to the estimate of $h^{2}=0.41$ for the $49^{\circ} \mathrm{C} \mathrm{TW}$ test and to those of other nociceptive measures reported by Mogil et al. (1999a).

As can be appreciated from visual inspection of Figure 1, these traits appear to be positively correlated genetically. Pearson's product-moment $\left(r_{\mathrm{p}}\right)$ and Spearman's rank $\left(r_{\mathrm{s}}\right)$ correlation coefficients confirming this impression statistically are presented in Table 1, and a scatterplot matrix showing the regression of strain ranks for the three tests is shown in Figure 2. We chose to plot strain ranks, because the relations between the raw data were nonlinear (data not shown). Of the six correlation coefficients generated (three $r_{\mathrm{p}}$ and three $r_{\mathrm{s}}$ ), four were significant after Bonferroni correction for multiple comparisons, and a fifth approached significance ( $p=0.07$ ). Practical limitations prevented us from purchasing and testing more strains to increase statistical power. Nonetheless, the clear conclusion overall is that a high degree of positive genetic correlation exists among these assays.

\section{DISCUSSION}

This study is to our knowledge the first to demonstrate genetic variation of responding to noxious cold in the mouse. It is known that humans display large interindividual differences in cold pain thresholds, ranging from 18.3 to $-4.8^{\circ} \mathrm{C}$ (Chery-Croze, 1983). Cold pain tolerance, assessed via the commonly used cold pressor test, is also known to display considerable variability, with bimodal "sensitive" and "insensitive" groups being identified with tolerance means of 50 and >180 sec, respectively (Chen et al., 1989).

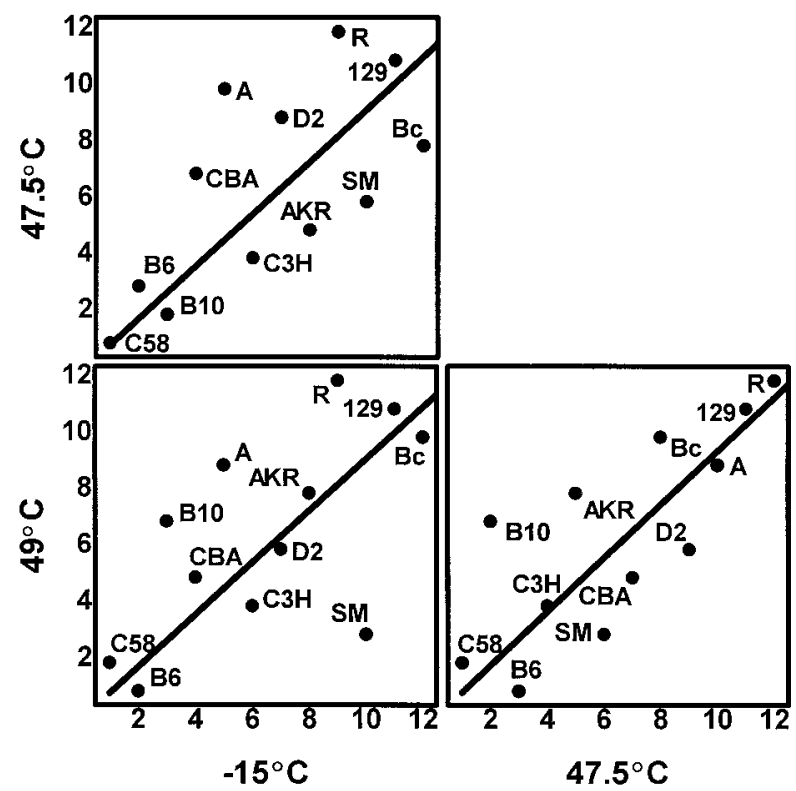

Figure 2. Genetic correlation between nociceptive sensitivity to different noxious water temperatures: $-15,47.5$, and $49^{\circ} \mathrm{C}$. Symbols represent inbred mouse strains arranged by their rank order of sensitivity on each assay (1, most sensitive and shortest latencies; 12, least sensitive and longest latencies). Strains with longer names are abbreviated as follows: $B 6, \mathrm{C} 57 \mathrm{BL} / 6 ; B 10,=\mathrm{C} 57 \mathrm{BL} / 10 ; B c, \mathrm{BALB} / \mathrm{c} ; C 3 H, \mathrm{C} 3 \mathrm{H} / \mathrm{He} ; D 2$, DBA/2; $R$, RIIIS. Spearman rank correlation coefficients range from 0.64 to 0.77 (see Table 1).

\section{Genetic correlations of nociceptive sensitivity}

The present data clearly indicate that genetic sensitivity to noxious cold correlates positively and strongly with responding to noxious heat. Such genetic correlations imply (subject to certain caveats; Carey, 1988) that the traits are mediated by similar genes, with pleiotropic (i.e., multiple) physiological effects (see Crabbe et al., 1990). A particular allele of a relevant gene will affect all traits in which that gene participates in the same (or opposite, if the correlation is negative) direction. If two traits are genetically correlated, therefore, a strain sensitive to the first-possessing "sensitivity" alleles of one or more genes affecting the trait-will be more likely to be sensitive to the second, and vice versa. In turn, the fact that traits share genes implies that they share physiology as well, that the same proteins are involved in their neural transduction and processing. Thus, we propose that the present data suggest at least partial physiological commonality of heat and cold nociception.

The strong correlation between sensitivity on the $47.5^{\circ} \mathrm{C} \mathrm{TW}$ test assessed presently with the $49^{\circ} \mathrm{C}$ TW test assessed previously (by the same investigator but in a different laboratory) can be viewed as an important confirmation and extension of our previous findings. First, it appears that stimulus intensity does not affect genetic mediation of thermal nociception even over a twofold range of grand mean latencies $\left(3.8 \mathrm{sec}\right.$ for $49^{\circ} \mathrm{C}, 8.1 \mathrm{sec}$ for $\left.47.5^{\circ} \mathrm{C}\right)$. This fact has also been demonstrated for the hot plate test (Elmer et al., 1997) and contradicts somewhat the notion of a fundamental dissociation between mechanisms underlying mild and intense pain (Millan, 1989; Parsons and Headley, 1989; Yeomans et al., 1996; Cao et al., 1998).

Second, because the $47.5^{\circ} \mathrm{C} \mathrm{TW}$ experiment afforded a unique opportunity to eliminate many sources of environmental variance (e.g., age, housing, habituation, circadian variance, and day-to- 
day variability), and strain sensitivities were nonetheless found to parallel those previously obtained at $49^{\circ} \mathrm{C}$, we are more confident that these strain differences reflect the influence of additive genetic variance rather than shared environmental variance or gene $\times$ environment interactions. These data stand in contrast to those of Crabbe and colleagues (1999), who demonstrated large effects of unidentified (and thus uncontrolled) environmental factors on the behavioral responses of inbred and transgenic mice. Our ability to faithfully replicate strain differences in thermal nociception in different laboratories with different equipment may derive from the higher heritability of this trait than many of those studied by Crabbe et al. (1999).

Finally, it should also be noted that the correlations among $-15^{\circ} \mathrm{C} \mathrm{CTW}, 47.5^{\circ} \mathrm{C} \mathrm{TW}$, and the other previously identified members of the "thermal cluster" (HP, HT, and autotomy) (Mogil et al., 1999b) are all in the moderate positive range $\left(r_{\mathrm{s}}=\right.$ $0.20-0.73)$. In fact, many of these correlations would be much higher if not for the existence of "outlier" strains. For example, RIIIS mice exhibit low TW and CTW sensitivity but high HP and HT sensitivity. C58 mice exhibit high sensitivity to all members of the thermal cluster except autotomy, to which they are profoundly resistant. As we have previously suggested, the further study of these strains may be of value in identifying genes with more specific roles in the mediation of each trait.

\section{The neurophysiology of cold pain}

Despite the prevalence of cold allodynia and hyperalgesia in individuals with inflammatory injury, nerve injury or central (poststroke) pain syndromes, very little is known about the neural processing of this noxious modality relative to heat. Part of the problem stems from confusion regarding the threshold for noxious cold. Nocifensive responses to cold have been noted at temperatures as high as $20^{\circ} \mathrm{C}$, but the threshold of many coldsensitive nociceptors is $\leq 0^{\circ} \mathrm{C}$ (Simone and Kajander, 1996), and c-fos expression is not induced by cold stimuli until $-15^{\circ} \mathrm{C}(\mathrm{Ab}-$ badie et al., 1994). Many electrophysiological experiments may have been conducted using temperatures too high to be truly relevant to cold pain (cf. Simone and Kajander, 1996), and it is now quite clear that innocuous "cool" is processed quite differently from noxious cold (Chen et al., 1996). The considerable variability in cold nociception noted herein may also have contributed to the confusion, because different investigators have no doubt experimented on subjects with differing genotypes.

It remains contentious as to whether noxious cold is processed similarly or differently than noxious heat by the nervous system. At the level of the peripheral nervous system, $\mathrm{A} \delta$ and $\mathrm{C}$ afferents have been identified that respond to noxious cold (e.g., Georgopoulos, 1976). In the only study in the mouse of which we are aware, Koltzenburg and colleagues (1997) found that noxious cold $\left(5^{\circ} \mathrm{C}\right)$ stimuli selectively activated 1 of $10 \mathrm{~A} \delta$ (high-threshold mechanoreceptor) and 3 of $10 \mathrm{C}$ fibers; one $\mathrm{C}$ fiber responded to both heat and cold. Overall, the proportion and location of cold-responding afferents and their cold specificity remain a matter of debate, although Simone and Kajander (1996) reported that all cutaneous heat-sensitive $\mathrm{C}$ fibers they tested were also excited by noxious cold of sufficient intensity.

In the spinal cord, temperature specificity appears to be lost for noxious stimuli. Many wide dynamic range (WDR) neurons in deep dorsal horn respond to both noxious heat and cold (Kenshalo et al., 1982). Of the two major types of lamina I spinothalamic tract cells receiving input regarding skin cooling, coolspecific (COLD) cells and multimodal "heat, pinch, and cold"
(HPC) cells, it is the latter that respond best to stimuli in the noxious range (e.g., Kenshalo et al., 1982; Craig and Bushnell, 1994). Morphine, which suppresses both heat and cold pain in humans, inhibits HPC cells but actually enhances the firing of COLD cells (Craig and Hunsley, 1991). Blocking conduction of myelinated fibers can raise the threshold of cold pain, converting the sensation to one of burning (e.g., Fruhstorfer, 1984). The "thermal grill" illusion and central pain syndrome also feature "burning cold." All three phenomena may share underlying central mechanisms, involving the opposing activity of HPC and COLD cells, and resultant thalamic disinhibition (see Craig, 1998). A finding suggesting the independence of hot and cold nociception at the spinal level is that of Tiseo and colleagues (1990), who observed a $\kappa$-opioid-dependent, noxious cold-specific release of substance $\mathrm{P}$ in the spinal cord, in contrast to a noxious heat-specific release of somatostatin. However, both types of thermal stimuli have been shown to induce substance $\mathrm{P}$ receptor internalization in spinal cord neurons (Allen et al., 1997).

Despite much evidence for convergence of heat and cold processing in the periphery and spinal cord, these modalities may be separable at higher levels of the nervous system. Neurons have been identified in the rat parabrachial nuclei responding specifically to noxious cold, although many cold-sensitive cells in this area were also driven by heat and/or pinch (Menendez et al., 1996). Functional imaging studies in humans have revealed differences in the pattern of cortical and thalamic activation produced by these stimuli, although considerable similarity exists in many regions as well (Casey et al., 1996; Craig et al., 1996; Davis et al., 1998). Nociception in the TW versus CTW tests can be differentially inhibited by supraspinally administered opioids, with the CTW test less sensitive to $\mu$ agonists but more sensitive to $\delta$ and $\kappa$ agonists than the TW test (Tiseo et al., 1988; Adams et al., 1993). Finally, Morin and Bushnell (1998) observed that human subjects chose different verbal descriptors to describe 48 and $-5^{\circ} \mathrm{C}$ stimuli applied to the hand, indicating unique qualitative experiences.

\section{Conclusions and human relevance}

The present finding that hot and cold nociception are genetically correlated in mice should not be interpreted as solving this debate in favor of convergent processing. However, the demonstration that similar genes are relevant to individual differences in sensitivity to these two thermal modalities does imply that they have at least some common physiology. Furthermore, these data show that within the physiological mechanisms common to these traits lie the polymorphic proteins (coded for by allelic variants of genes) accounting for the strain differences noted herein. Thus, existing (Mogil et al., 1997) and ongoing gene-mapping studies in our laboratory of heat nociception should be of relevance to coldnociception as well. The fact that the genetic correlations fall short of 1.0 leaves open the possibility that certain genes contribute uniquely to heat and cold pain. However, because shared environmental covariance (e.g., maternal effects and litter sizes) practically limits the size of genetic correlations in behavioral experiments, correlations of the magnitude noted presently are convincing.

It is difficult to speculate on the nature of the genes responsible for variability in thermal nociception. Such genes could be involved in peripheral processes, such as determining the survivability and/or function of nociceptive afferents (e.g., neurotrophic or differentiation factors and ion channels) or the functioning of nociception-related spinal or supraspinal neurons (e.g., neuropeptides, receptors, and enzymes). If hot and cold noxious 
stimuli are activating the same afferents (C fibers) and/or spinal neurons (WDR or, as is especially likely, HPC cells), then the same allelic variants of relevant genes would affect both modalities similarly. It is also entirely possible, of course, that the genes in question play roles in determining, for example, the thickness of the cornified layers of the skin, cutaneous blood flow (noting that the tail is a major vasomotor organ in rodents), and stress responses (noting that these nociceptive assays involve restraint). One of the advantages of using a linkage mapping approach to gene identification is that one is not forced to prioritize among these choices. A mapping investigation of $49^{\circ} \mathrm{C} \mathrm{TW}$ sensitivity is currently under way in our laboratory, the results of which will hopefully shed light on these issues for hot and cold pain alike.

Finally, it should be noted that the question of correlation of sensitivity to experimental pain tests in humans is also highly contentious. Only four studies have directly compared heat and cold pain sensitivity in humans. Wolff and Jarvik (1964) demonstrated a significant correlation $(r=0.42)$ between thresholds to radiant heat and cold pressor, whereas other investigators found weak or no correlations (Davidson and McDougall, 1969; Lynn and Perl, 1977; Janal et al., 1994). As pointed out by Kreh et al. (1984), it is unclear whether the cold pressor test $\left(0-5^{\circ} \mathrm{C}\right)$ used as a "cold" stimulus in these studies is equivalent to the considerably more noxious $-15^{\circ} \mathrm{C}$ stimulus used presently.

\section{REFERENCES}

Abbadie C, Honore P, Besson J-M (1994) Intense cold noxious stimulation of the rat hindpaw induces c-fos expression in lumbar spinal cord neurons. Neuroscience 59:457-468.

Adams JU, Tallarida RJ, Geller EB, Adler MW (1993) Isobolographic superadditivity between delta and $m u$ opioid agonists in the rat depends on the ratio of compounds, the $m u$ agonist and the analgesic assay used. J Pharmacol Exp Ther 266:1261-1267.

Allen BJ, Rogers SD, Ghilardi JR, Menning PM, Kuskowski MA, Basbaum AI, Simone DA, Mantyh PW (1997) Noxious cutaneous thermal stimuli induce a graded release of endogenous substance $\mathrm{P}$ in the spinal cord: imaging peptide action in vivo. J Neurosci 17:5921-5927.

Cao YQ, Mantyh PW, Carlson EJ, Gillespie A-M, Epstein CJ, Basbaum AI (1998) Primary afferent tachykinins are required to experience moderate to intense pain. Nature 392:390-394.

Carey G (1988) Inference about genetic correlations. Behav Genet 18:329-338.

Casey KL, Minoshima S, Morrow TJ, Koeppe RA (1996) Comparison of human cerebral activation pattern during cutaneous warmth, heat pain, and deep cold pain. J Neurophysiol 76:571-581.

Chen ACN, Dworkin SF, Haug J (1989) Human pain responsivity in a tonic pain model: psychological determinants. Pain 37:143-160.

Chen C-C, Rainville P, Bushnell MC (1996) Noxious and innocuous cold discrimination in humans: evidence for separate afferent channels. Pain 68:33-43.

Chery-Croze S (1983) Relationship between noxious cold stimuli and the magnitude of pain sensation in man. Pain 15:265-269.

Crabbe JC, Phillips TJ, Kosobud A, Belknap JK (1990) Estimation of genetic correlation: interpretation of experiments using selectively bred and inbred animals. Alcohol Clin Exp Res 14:141-151.

Crabbe JC, Wahlsten D, Dudek BC (1999) Genetics of mouse behavior: interactions with laboratory environment. Science 284:1670-1672.

Craig AD (1998) A new version of the thalamic disinhibition hypothesis of central pain. Pain Forum 7:1-14.

Craig AD, Bushnell MC (1994) The thermal grill illusion: unmasking the burn of cold pain. Science 265:252-255.

Craig AD, Hunsley SJ (1991) Morphine enhances the activity of thermoreceptive cold-specific lamina I spinothalamic neurons in the cat. Brain Res 558:93-97.

Craig AD, Reiman EM, Evans A, Bushnell MC (1996) Functional imaging of an illusion of pain. Nature 384:258-260.

Daum PS, Bowers Jr WD, Tejada J, Morehouse D, Hamlet MP (1991) Cooling to heat of fusion (HOF), followed by rapid rewarming, does not reduce the integrity of microvascular corrosion casts. Cryobiology 28:294-301.
Davidson PO, McDougall CEA (1969) The generality of pain tolerance. J Psychosom Res 13:83-89.

Davis KD, Kwan CL, Crawley AP, Mikulis DJ (1998) Functional MRI study of thalamic and cortical activations evoked by cutaneous heat, cold, and tactile stimuli. J Neurophysiol 80:1533-1546.

Elmer GI, Pieper JO, Negus SS, Woods JH (1997) Genetic variance in innate nociception and its relationship to the potency of morphineinduced analgesia in thermal and chemical tests. Pain 75:129-140.

Falconer DS, Mackay TFC (1996) Introduction to quantitative genetics. Essex, UK: Longman.

Fruhstorfer H (1984) Thermal sensibility changes during ischemic nerve block. Pain 20:355-361.

Georgopoulos AP (1976) Functional properties of primary afferent units probably related to pain mechanisms in primate glabrous skin. J Neurophysiol 39:71-83.

Hegmann JP, Possidente B (1981) Estimating genetic correlations from inbred strains. Behav Genet 11:103-114.

Janal MN, Glusman M, Kuhl JP, Clark WC (1994) On the absence of correlation between responses to noxious heat, cold, electrical and ischemic stimulation. Pain 58:403-411.

Kenshalo Jr DR, Leonard RB, Chung JM, Willis WD (1982) Facilitation of the responses of primate spinothalamic cells to cold and to tactile stimuli by noxious heating of the skin. Pain 12:141-152.

Koltzenburg M, Stucky CL, Lewin GR (1997) Receptive properties of mouse sensory neurons innervating hairy skin. J Neurophysiol 78:1841-1850.

Kreh A, Anton F, Gilly H, Handwerker HO (1984) Vascular reactions correlated with pain due to cold. Exp Neurol 85:533-546.

Lynn B, Perl E (1977) A comparison of four tests for assessing the pain sensitivity of different subjects and test areas. Pain 3:353-365.

Menendez L, Bester H, Besson JM, Bernard JF (1996) Parabrachial area: electrophysiological evidence for an involvement in cold nociception. J Neurophysiol 75:2099-2116.

Millan MJ (1989) Kappa-opioid receptor-mediated antinociception in the rat. I. Comparative actions of mu- and kappa-opioids against noxious thermal, pressure and electrical stimuli. J Pharmacol Exp Ther 251:334-341.

Mogil JS (1999) The genetic mediation of individual differences in sensitivity to pain and its inhibition. Proc Natl Acad Sci USA 96:7744-7751.

Mogil JS, Richards SP, O’Toole LA, Helms ML, Mitchell SR, Belknap JK (1997) Genetic sensitivity to hot-plate nociception in DBA/2J and C57BL/6J inbred mouse strains: possible sex-specific mediation by $\delta_{2}$-opioid receptors. Pain 70:267-277.

Mogil JS, Wilson SG, Bon K, Lee SE, Chung K, Raber P, Pieper JO, Hain HS, Belknap JK, Hubert L, Elmer GI, Chung JM, Devor M (1999a) Heritability of nociception. I. Responses of eleven inbred mouse strains on twelve measures of nociception. Pain 80:67-82.

Mogil JS, Wilson SG, Bon K, Lee SE, Chung K, Raber P, Pieper JO, Hain HS, Belknap JK, Hubert L, Elmer GI, Chung JM, Devor M (1999b) Heritability of nociception. II. "Types" of nociception revealed by genetic correlation analysis. Pain 80:83-93.

Morin C, Bushnell MC (1998) Temporal and qualitative properties of cold pain and heat pain: a psychophysical study. Pain 74:67-73.

Parsons CG, Headley PM (1989) Spinal antinociceptive actions of $\mu$ - and $\kappa$-opioids: the importance of stimulus intensity in determining "selectivity" between reflexes to different modalities of noxious stimulus. Br J Pharmacol 98:523-532.

Pizziketti RJ, Pressman NS, Geller EB, Cowan A, Adler MW (1985) Rat cold water tail-flick: a novel analgesic test that distinguishes opioid agonists from mixed agonist-antagonists. Eur J Pharmacol 119:23-29.

Simone DA, Kajander KC (1996) Excitation of rat cutaneous nociceptors by noxious cold. Neurosci Lett 213:53-56.

Tiseo PJ, Adler MW, Liu-Chen L-Y (1990) Differential release of substance $\mathrm{P}$ and somatostatin in the rat spinal cord in response to noxious cold and heat; effect of dynorphin $\mathrm{A}_{(1-17)}$. J Pharmacol Exp Ther 252:539-545.

Tiseo PJ, Geller EB, Adler MW (1988) Antinociceptive action of intracerebroventricularly administered dynorphin and other opioid peptides in the rat. J Pharmacol Exp Ther 246:449-453.

Wolff BB, Jarvik ME (1964) Relationship between superficial and deep somatic thresholds of pain with a note on handedness. Am J Psychol 77:589-599.

Yeomans DC, Pirec V, Proudfit HK (1996) Nociceptive responses to high and low rates of noxious cutaneous heating are mediated by different nociceptors in the rat: behavioral evidence. Pain 68:133-140. 